
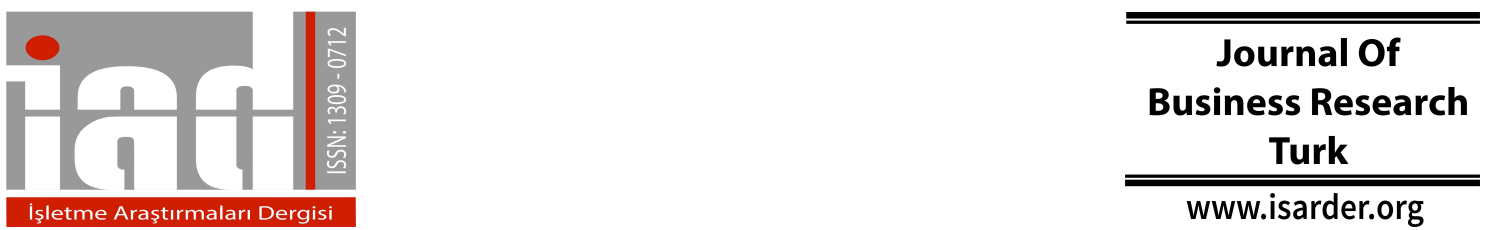

\title{
Career Choices of Business Administration Students: A Turkish Case
}

\author{
Elif KARABULUT TEMEL \\ Abant İzzet Baysal University \\ Faculty of Economics and Administrative \\ Sciences, Department of Business \\ Administration \\ Bolu, Turkey \\ orcid.org/0000-0002-8861-890X \\ temel e@ibu.edu.tr
}

\author{
Hülya ERKANLI \\ Abant İzzet Baysal University \\ Faculty of Economics and Administrative \\ Sciences, Department of Business \\ Administration \\ Bolu, Turkey \\ orcid.org/0000-0002-7747-8673 \\ erkanli h@ibu.edu.tr
}

\begin{abstract}
The purpose of the study is to understand the reasons of students' choosing business administration department, to identify these students' career expectations and concerns, and to realize the changes and the reasons of the changes in their career choices and expectations through the education process. The study was conducted at business administration department of a state university located in a small city in Turkey. In-depth interviews were conducted with 40 volunteer undergraduate BA students both at their freshman and senior years. The university entrance exam scores and family socio-economic status of the students are the main factors influencing their choice of BA education. It has been observed that students are mainly affected from the opinions of their friends and the social environment they are in when deciding the field of work they will be choosing upon their graduation and that internships and part time work usually help them reach clarity where their career objectives are concerned. The data collection process has been performed in the freshmen year of the students and repeated in the senior year they graduate from university. The fact that the study has been completed in a period of 4 years adds to its authentic value.
\end{abstract}

Keywords: Career choice, career goals, business administration students

\section{Introduction}

According to Super (1957), career choices are attempts oriented to put the skills, competencies and interests that reflect the individual's own personality into practice. When the subject is university students, career objectives reveal themselves to be the possible versions of the subject matter person. The possible version of the person, and the ones avoided, define the career path that person would take, thus creating a motivation for the said person (Pizzolato, 2007). The factors that affect the career development are usually under the influence of personal, societal and economic determinants and develop as a result of the interaction of the fields that shape up the person's identity (Tanova, Karataş Özkan and İnal, 2008). The alternative career choices that are valid for a time for a person are generally affected from factors such as 
the labor market and economic status as well as education, family structure and behaviors of that person. Within this context, career selection is structured under the influence of the socio-cultural, personal factors, cultural values, significant relationships and structural factors and as such, on the whole, its structure is also restricted by these factors (Agarwala, 2008; Lent and Brown, 1996; Lent, Brown and Hackett, 2000). Lent and Brown (1996) visualizes the process in which a university student faces his career choice as the focal point of a circle surrounded by factors such as the friendships, financial status and family's influence that affect and influence this decision. The family factor has significant influence on the intentions of a person regarding his career choice. The influence of the family is one of contextual determinants that mediates the relationships among interests, goals, actions and achievements.

The family, the social and economic status of the parents in particular, has an impact on the educational and vocational means available to the individual as well as the things a person could achieve and as such have a profound effect on many aspects of a person's life. The socio-economic status of the family affects the development process of the child's interest in various career choices, determination of their career goals and their attitudes, where their careers are concerned (Dhesi, 2001; Duffy and Sedlacek, 2007; Eccles, 1992; Krumboltz, 1976; Murnane, Maynard and Ohls, 1981; Wong and Liu, 2010). In addition to the family, it is also possible to consider the influence of personal values as a behavioral determinant and attitudes on the choice of and their leniency towards a career (Dries, 2011; Inglehart, 2008). As Holland (1997) mentioned personal and environmental factors can be associated with vocational choice and vocational achievement. Personal and environmental discovery together provide useful information on the overlap of the interests and competencies of a person with specific fields of work and within this context information is also provided for career tendency on which a harmony of personal and environmental factors could be achieved. There are many studies that examine the effects of personal and environmental discovery on the career choices of the individual (Gianakos, 1999; Junk and Armstrong, 2010; Nazli, 2007; Ng, Burke and Fiksenbaum, 2008). In resources pertaining to the choice of career, it is possible to see studies examining the effects of the culture a person is embroiled in on his/her career choices (Ayala and Oshrit, 2008; Counsell, 1999; Derr and Laurent, 1989; Leong, Hardin and Gupta, 2010; Thomas and Inkson, 2007; Vigoda-Gadot and Grimland, 2008).

College education is one of the ways in choosing among potential career paths. Ideally, a career decision is made before getting into college education because it takes significant amount of time, effort and financial resources to obtain a college degree. While different countries employ different methods in going into college education, they usually involve some sort of an entrance exam. In Turkey it is a two-stage examination where students who can pass the first stage are allowed to take the second stage exam. Then the students pick the departments they want to study based on their second stage exam score.

Although the students decide and choose the academic department they will study, many of our students have asked questions related to their future career prospects. We realized that there is significant amount of anxiety about employment and uncertainty about career path the students would take upon graduation. These observations suggested widespread career indecision among the BA students. While there is a study investigating the factors influencing career choices of BA students (Akoğlan Kozak and 
Dalkıranoğlu, 2013; Aycan and Fikret-Pasa, 2003; Telli Yamamoto, 2006), there is no study on career indecision and changes in career choices during college education in Turkey. Therefore, this study was designed 1) to investigate students' reasons for choosing BA department, 2) to determine the career goals in mind when BA was chosen, and 3) to examine the factors influencing changes in these career goals during four years of college education. The study was conducted with 40 volunteer BA students at a state university in Turkey between 2010 and 2014.

\section{Method}

\section{Participants}

The study was conducted with business administration (BA) students at a state university in Turkey between 2010 and 2014. Of the total 245 (135 females, 110 males) registered freshmen in the BA department in 2010, 40 (21 females, 19 males) students volunteered to take part in the study. The ideal size in a qualitative research is between 15 and 40 respondents (Marchall, Cardon, Poddar and Fontenot, 2013). Since 40 students volunteered to take part in the study and this number corresponds to the ideal size, all volunteer students were interviewed for the study. Ages of the students ranged from 18 to 20. The same 40 students were interviewed twice, in their freshman (2010) and senior (2014) year of college education.

\section{Procedure}

The study was announced at the department. The volunteer students were given appointments for the in-depth interviews. In-depth interview technique was preferred for several reasons. First of all, career aspirations of college age students can be a sensitive issue to gather information on (Robbins, Wallis and Dunston, 2003) and the factors influencing these may be considered private. In-depth interviews provide a comfortable environment and in-person contact that facilitate trust (Adams and Cox, 2008). Thus, more reliable answers can be gathered and deeper insight may be gained. Second, one of the goals of this study is to explore changes in the career goals during college education. The authors are more interested in understanding how these changes occur and how they are related, rather than only measuring the relationship between variables which can be achieved through a qualitative approach . Finally, it was believed that qualitative research would allow researchers to gain a deeper understanding of career indecision of the participants in terms of answering what, how, when and why questions, which would be more effective in revealing participants' true thoughts on their careers compared to employing a quantitative research approach.

More detailed information can be gathered by in-depth interviews because it allows follow-up questions to understand participants more thoroughly (Johns and Ross-Lee, 1998). Based on this approach, a structured interview question form was assembled based on career studies in the literature (Agarwala, 2008; Akoğlan Kozak and Dalkıranoğlu, 2013; Aycan and Fikret-Pasa, 2003; Chiesa, Massei and Guglielmi, 2016; Gianakos, 1999; Ng, Burke and Fiksenbaum, 2008; Ozbilgin, Kusku and Erdogmus, 2005; Telli Yamamoto, 2006; Vigoda-Gadot and Grimland, 2008; Wong and Liu, 2010). At the beginning of the interview the students were informed that the study is long term and there will be a second interview in their senior year and their contact information was recorded. Interview questions for the first year is made up of questions related to demographic factors (including family income and parents' education levels), 
student accommodation, reasons for choosing BA department, employment concerns after graduation, and what kind of careers were envisioned with their reasons.

Before conducting interviews with the same participants in the last year, the authors studied each participant's responses in the first interview. Except for demographics and reasons for choosing BA department, the same questions in the first interview were directed to the participants. When a different answer was received to the same question asked four years ago, reasons for the change were investigated through follow-up questions.

All interviews were conducted by both authors in the same room. The interviewers (the authors) took notes independently during the interviews and compared these notes after the interview. Each interview took 20 to 30 minutes. In order to maintain objectivity, directive questions were avoided. A descriptive analysis was conducted and information gathered from the students narrated in quotes.

In-depth interviews were evaluated qualitatively. With regards to students' reasons for choosing BA department, career goals at the beginning of their higher education, changes in these goals during four-year long university education and the factors influencing career goals and changes in them representative quotes were selected and presented.

\section{Findings}

The main themes that emerged from the in-depth interviews can be addressed in 4 main categories; family characteristics of the students, reasons for choosing business administration department, employment concerns, and changes in career choices in time. In Table-1, main themes and sub-themes are shown together.

Table-1 Theme Categorization of In-Depth Interview Findings

\begin{tabular}{|l|l|}
\hline \multicolumn{2}{|l|}{ Family Characteristics of The Students } \\
\hline & Education Level \\
\hline & Income Level \\
\hline Views About The Reasons For Choosing Business Administration Department \\
\hline & Choice By Their Own Interest To This Field of Study \\
\hline & Life Quality Expectations \\
\hline & Scores In The Entrance Exam \\
\hline Views About The Employment Concerns \\
\hline \multicolumn{2}{|c|}{ Diffucult To Find A Job Upon Graduation } \\
\hline Views About The Changes In Career Choices In Time \\
\hline \multicolumn{2}{|c|}{ Public Sector } \\
\hline & Private Sector \\
\hline
\end{tabular}

Family Characteristics of the Students

About half of the parents did not have education beyond primary school and the proportion of college graduates among the parents was very low. Overwhelming majority of students' families had monthly income of less than 3,500 Turkish Liras (Table-2), which is the poverty threshold for a family of four for the year 2010 (The Turkish Statistical Institute, http://www.turkstat.gov.tr/PreTablo.do?alt_id=1013). 
Table-2 Family Characteristics of the Students

\begin{tabular}{|c|c|c|c|c|}
\hline \multicolumn{5}{|c|}{ Parents' Education Levels } \\
\hline & \multicolumn{2}{|c|}{ Mother } & \multicolumn{2}{|c|}{ Father $(\mathrm{N})$} \\
\hline & $\mathrm{N}$ & $\%$ & $\mathrm{~N}$ & $\%$ \\
\hline Illiterate & 2 & 5 & 1 & 2,5 \\
\hline Primary School & 25 & 62,5 & 16 & 40 \\
\hline Middle School & 2 & 5 & 5 & 12,5 \\
\hline High School & 8 & 20 & 12 & 30 \\
\hline University & 3 & 7,5 & 6 & 15 \\
\hline Total & 40 & 100 & 40 & 100 \\
\hline \multicolumn{5}{|c|}{ Family Income Level } \\
\hline & \multicolumn{3}{|c|}{$\mathrm{N}$} & $\%$ \\
\hline 1000 or lower & \multicolumn{3}{|c|}{1} & 2,5 \\
\hline $1001-2000$ & \multicolumn{3}{|c|}{6} & 15 \\
\hline $2001-3500$ & \multicolumn{3}{|c|}{30} & 75 \\
\hline $3501-5000$ & \multirow{2}{*}{\multicolumn{2}{|c|}{2}} & \multicolumn{2}{|r|}{5} \\
\hline 5000 or more & & & \multicolumn{2}{|r|}{2,5} \\
\hline Total & \multicolumn{2}{|r|}{40} & \multicolumn{2}{|r|}{100} \\
\hline
\end{tabular}

The education and income levels of the families influence the career choices of the students. The quotes taken from in the interviews are as follows:

"I could not go to a private teaching institution because of my family's economic situation. I was just able to get here with the possibilities I have"

"Because of our economic situation, my family said that I could only get education where we live. We live in this city so, I chose here.

\section{Reasons for Choosing Business Administration Department}

Five students $(12,5 \%)$ chose BA department solely because they wanted to be in this field and $13(32,5 \%)$ students based on belief that the life quality would be good and the monetary return of education would be high upon graduation. Majority of the students (22 students, $55 \%$ ), however, chose this department for the sole reason that their scores in the entrance exams rendered them eligible for this department, and primary choice of these students would have been psychology or teaching.

According to the interviews, it is possible to examine the reasons for choosing business administration department in three main categories; choice by their own interest to this field of study, life quality expectations, scores in the entrance exam. The distribution of students according to these categories can be seen in Table-3.

Tablo-3 Views About the Reasons for Choosing Business Administration Department

\begin{tabular}{|l|c|c|}
\hline $\begin{array}{l}\text { Reasons for Choosing Business } \\
\text { Administration }\end{array}$ & N & \% \\
\hline $\begin{array}{l}\text { Choice by Their Own Interest To This } \\
\text { Field of Study }\end{array}$ & 5 & 12,5 \\
\hline Life Quality Expectations & 13 & 32,5 \\
\hline Scores in the Entrance Exam & 22 & 55 \\
\hline Total & $\mathbf{4 0}$ & $\mathbf{1 0 0}$ \\
\hline
\end{tabular}


The quotes taken from students during interviews as to their preference of the Business Administration due to their eligibility based on their exam scores reveals the following circumstances.

"My first choice was psychology as I consider it to be a profession with the highest level of human contact. But my score was inadequate so I wrote business administration and my reason for choosing this subject to study was again the close contact with other people."

"I wanted to be a teacher but my exam score was sufficient for business administration, however, I am planning on taking the exam again to switch to teaching."

"I am here due to my eligibility on the basis of my exam score, regardless of the fact that I do not want to do office work. I am normally ambitious however this is a field I am not keen on and consequently I do not feel ambitious at all."

"My score was good for business administration. This was the third university exam I took. It was my wish to branch into teaching but I could not do it. I have no willpower left to get ready for another entrance exam. Before the exam I decided to go into whichever subject my score would render me eligible for, and it came out to be business administration."

Additionally, the belief that the quality of their life would be good and the monetary return of their education would be high upon graduation from this department steers many students into studying the subject. The quotes taken from in the interviews support this point of view.

"If I study business administration, I can become an executive and with selfdevelopment I can become rich."

"My dad is a worker at the factory. I want to be like the executives there. My primary goal is to be financially comfortable."

"My mother was the caretaker to the kids of bank managers. Seeing how their standard of life was elevated she wanted me to be educated in business administration. That is why I chose this field."

"I want my income level to be high. The sum of our monthly expenses is what CEOs spend in a day."

On the other hand students, who chose business administration solely because they wanted to be in this field, express their thoughts as follows.

"Being a graduate of business administration means you are on top of things. For this reason I switched out of law into business administration."

"I have been interested in economics and finance since I was in secondary school. I have always been interested in the machinations of the private sector. I do not think I would ever work for the government. That is why my choice of subject in the university was business administration."

"I wanted to be in this field and I'm studying business administration by choice. It has always been my desire to become an entrepreneur." 


\section{Employment Concerns}

While some of the students stated that they have concerns about finding a job, some of them stated that they don't have any concerns about finding a job. For some students these views change over time due to different reasons. Realizing the fact that there are too many business graduates increases the students' employment concerns. Students feel obligated to make a difference in order to improve their job finding prospects. On the other hand, according to interviews, having work experience while studying in university reduces employment concerns. Some quotes from the interviews of the students are as follows:

"There are many students graduating from business administration. If I do not improve myself I will not be able to find a job."

"I feel bad when I tell people that I study Business Administration due to the large number of graduates."

"I do not think anybody would hire you if you do not have an influential person backing you, this raises concerns in regards to finding a job."

"I have worked in two different places throughout my university life. It gave me confidence. I do not think I will have difficulty finding a job when I graduate"

\section{Changes in Career Choices}

The proportion of students wishing to be employed in the public sector by taking the public sector entrance exam has more than doubled in their senior year compared to their freshman year (from 8 students to 17 students). The reason for this phenomenon appears to be as follows as revealed by the quotes from the interviews.

"I wanted to be an entrepreneur when I first started school. Other students have shown some tendency to work for the public sector. This situation has also affected me. I plan on working for the public sector too."

"I would like to take the civil servant selection exam to become a public sector employee. At least the weekends are yours to enjoy along with the job security such an occupation provides."

"The older students that we share the house with started working for the public sector upon finishing the school. I want to be like them."

The quotes from the comments of students that have chosen business administration but are now indecisive about the path that their careers would take are as follows:

"When I first started my studies in the department I wanted to become a banker. Later on I interned at a bank and realized that banking is not suitable for me due to the excessively long work hours."

"Upon finishing the school, I would like to dabble in politics and contribute to the development of the city I live in. If I could not become a politician I would like to take the civil servant selection exam and become an executive at a public sector company. If these two options do not pan out, I can work in the real estate sector or open an auto gallery." 
"This was not a field that I have been dreaming about; therefore I have no set plans for the future. I wanted to become an accountant in my freshman year. The next year I worked at a job that I liked very much. This gave me self-confidence. My job satisfaction is very high. I like jobs that I can use my creativity. I plan on working for the private sector."

"I found myself a job in my junior year. I started working. I was planning to become a civil servant when I first started university; however, now I want to establish my own business."

"Prior to starting the university I worked at different grocery markets. I was planning to open my own market. My friends at the university said they would be working for the government and I was affected by their opinions, however now I want to work for the private sector, make money and be an executive."

It has been observed that lack of any goals regarding the job they would be pursuing after graduation increases the degree to which the student is influenced by their friends' ideas and opinions. A similar situation can be observed as to the increase in the desire to be employed in the public sector. Students that chose to study business administration just because their exam scores rendered them eligible are influenced by their social circle due to the ambiguities they experience in regards to the job they would choose to be employed at.

Majority of the students experience financial hardship during their college education due to below poverty level income of their families. This desperation forces them to stay at apartments which are not a dormitory not a rental apartment but an apartment with a structured living code run by some organizations usually with religious tendencies and not regulated by the government. In the interviews conducted, students have indicated to be affected from the career choices of people, who are older and their senior, living in the same apartment with them. Some of the citations from the interviews on the subject are as follows:

"The income level of my family is low and I stay at this apartment for a nominal fee. Our older acquaintances promised to help us in finding jobs."

"When I first started university, I had to leave the city I was living then to move to a new one and a friend of my uncle met me. He told me about the apartments that I could stay at for a nominal fee. I found accommodation in one of those houses. Our roommates that have already graduated and left will help us find jobs at their workplaces upon our graduation."

"I stay at an apartment with some older roommates who are telling me to work for the public sector upon graduation. They have acquaintances and family members that could help them find jobs. They say they would try and help us in finding jobs."

Students who want to be employed in private sector believe their relatives would find them a job. Here are few quotes illustrating this situation.

"Upon my graduation my cousin will find me a job at the company he is currently employed."

"My aunt is the manager of a private bank and she told me she would find me a job when I graduate." 
"I have two uncles-in-law, who work for very good companies. They will find me a job upon my graduation."

\section{Discussion}

This study has intended to research the career choices of BA students and the factors that affect the choices they make; starting with the freshman year until the end of the senior year. Within this scope students who chose business administration as their field of study have been included within the study.

The main factors that influence the career choices of the students in this study have been their scores in the university entrance exam and the socio-economic level of their families. However, for these students the uncertainty they face at the point of determining their career choices during their education process regarding the field they will be working in, is a conspicuous fact.

University entrance system in Turkey is a two-stage test examination of high school graduates. The students make selection of the departments they would like to study once they receive their exam scores and are placed into one of their selected departments if their score is sufficient. According to the findings of the study, the major reason behind the preference of business administration by students was the fact that their scores in the university entrance exam rendered them eligible for this department. In a study conducted by Telli Yamamoto (2006), the university entrance exam scores have also been determined to play a role at the rate of $73 \%$ in the choices students make in regards to the subject they will be studying in Turkey. Therefore, the most important determining factor, where the career choices of the students are concerned, is the education system of the country and the processes implemented in connection with this. However, the findings reveal that although business administration is not a preferred field of study of the students, it is nevertheless viewed as something attainable, with good prospects for the future in terms of quality of life and high monetary returns when considered from the aspect of university entrance exam scores. Another factor that influences the career choices of students within the scope of the study has been the socio-economic level of the families involved. A person is brought to life and grows up within the confines of his/her family as well as being shaped by the beliefs and values of that family. A child's expectations are shaped by these factors. Families differ from each other in terms of the things they teach their children and the resources they could offer them. Such differences expose children from different families to different circumstances and as such lead to the diversification of a person's educational and functional preferences as well as his/her skills and choices (Krumboltz, 1976). Family educational variables, as stated by Eccles (1992), affect the beliefs and behaviors of parents and this indirectly influences the career outputs of their children. The subject that the parents have an impact on their children's career choices have also been supported by the results another study (Wong and Liu, 2010).

Socio-economic infrastructure, the characteristics of the family and the society in which the family exists play a role in shaping the expectations (Dhesi, 2001). The circumstances pertaining to family infrastructure determine the realities that the person could foresee as well as his perception of the benefits he/she can derive from his/her education (Dhesi, 2001; Murnane, Maynard and Ohls, 1981). However, the family values and behavioral patterns affect the socialization process. These processes ensure that the child gains an identity influenced by his family's goals and values and as such 
steer that persons expectations. It can be said that a family's financial means is a determinant of a person's capacity to invest in education (Dhesi, 2001). Even if the students decline to accept their families' influence on their career choices, the examination of other findings point to the impact of the socio-economic status of the family on the career choices of the student. The fact that income levels of the majority of the families of students that took part in the study were lower than the poverty threshold could be deemed as the main reason behind their expectations of better monetary returns and higher standards of life. As a matter of fact, in the study conducted by Duffy and Sedlacek (2007), students with family income levels below or above the general averages have been determined to be affected from the family environment negatively or positively based on the income concerned. Inglehart (2008) stated that the countries with lower income levels currently embrace the materialist values more. Therefore, in consideration of the fact that the poverty threshold is related to the economic status of the country, it can be said that this has an effect on the career choices of the people living in that country. A similar result was obtained in the study conducted by Akoğlan Kozak and Dalkıranoğlu (2013). Due to the concerns regarding the future, the material factors are given priority over career development opportunities. This steers the students in the direction of the fields that are considered more reliable and constant. At this point, the public sector reveals itself to be an area preferred highly in terms of jobs (Akoğlan Kozak and Dalkıranoğlu, 2013). The findings of the study as well as the increase in the proportion of the students wishing to work for the public sector as determined in the study conducted close to the graduation of the students are of the nature to support the results obtained in this study. However, a part of the students from low-income families stay in the houses provided by various organizations that provide affordable accommodation. The fact that these students do not have any clear career choices lead them to be influenced by the choices of other people staying in the same house with them.

Another conspicuous fact is the uncertainty these students face at the point of determining their career choices during their education process regarding the field they will be working in upon their graduation. It can be said that the level of awareness of the students was low that took part in the study, regarding available jobs, establishments and sectors vis-à-vis their fields of interest and career choices. Accordingly, it has also been observed that the fields of interest and the courses in which the student is successful have not also been influential in terms of bringing clarity to the fields in which the student wishes to work in the future. For example, a student that is interested in marketing or successful in marketing courses could choose to concentrate in some other area where job prospects are better. This demonstrates that these students have not yet reached the necessary level of awareness both on an individual level as well as in terms of the prospects available in their environment. However, it has also been observed that the students, who are involved in internships or work part-time during their university education, experience less uncertainty as their career decisions are concerned. The awareness of the person as an individual, experiences and the combination of these experiences with the opinions of others regarding the person constitute an integrated whole that is quite meaningful (Nazli, 2007; Super, 1957). The discovery of a person's identity points to a deeper perspective as oriented to a better understanding of a person's interests, values, and the self in deciding for a suitable career. Environmental discovery on the other hand, is the information gathering process in relation to the jobs, positions and sectors to ensure that a more informed career 
decision could be reached (Zikic and Richardson, 2007). The discovery of self and environment together provide information on the extent of overlap of a person's interests and skills with some specific fields of work and steers that person to a career choice whereby it is possible to achieve compatibility between individual and environmental factors (Ballout, 2007). According to Ozbilgin, Kusku and Erdogmus (2005) the perfect career choice is considered to be rare and an ignorant expectation or is characterized as a misguided belief due to the challenging and variable structure of suitable career alternatives (career routes) available in real life.

In addition to all the foregoing findings, the effect of the existing culture on the career choices is another factor that must also be taken into consideration. The behavior of a person is affected from the norms and dominant values of the society. These norms and values could have a restrictive or easing effect. Within this context, expectations from higher education could be higher in a social structure whereby social norms placing importance on learning and success are dominant. It is also possible to say that the opposite of this could also be true (Dhesi, 2001).

In the studies conducted by Hofstede (1991), it has specifically been emphasized that an understanding of national culture would be necessary to understand the individuals in various organizations. Derr and Laurent (1989) consider the national culture as a determinant factor in defining the career of a person. They emphasize that this process is defined by the fundamental beliefs of the person and the selected career path and job are based on early experiences in the family and life at school. National culture is what shapes the filters that ensure individuals perceive the business worldexternal career- in the same manner as others that view the world through the same cultural lens as the person (Counsell, 1999). In addition to the cultural differences stated the social, economic and political structures could also have an effect on the career choices. The similarities and differences between these structures among different countries could also lead to career patterns that display differences or similarities (Thomas and Inkson, 2007). In the study conducted by Ayala and Oshrit (2008), the differences between cultures are considered to be an important factor affecting the career choices in the area of management. In cultures where individualism stands out, the individuals are considered to be independent entity and in contrast to this in collectivist cultures the individuals are considered to be interdependent entity. Within this context, the decision making process in individualistic cultures is shaped according to the individual's own wishes and desires, while in collectivist cultures, the decisions are taken jointly in a group environment (together with the family, relatives, friends, etc.) (Aycan and Fikret-Pasa, 2003). In the light of the explanations made above, and in consideration of the findings, the students have been observed to be influenced by others where their career choices are concerned. Within this context, the individuals could be said to reflect more of collectivist characteristics. In individualistic cultures, the individuals have the tendency to change the business groups or the organizations they work for while collectivist cultures prefer to maintain the status quo as far as the job and the organization are concerned. In collectivist cultures where altruistic behavior is dominant, the way the people act according to specific behavioral patterns and the respect and prestige of the valued group of people are factors that gain significance (Vigoda-Gadot and Grimland, 2008). Persons from an individualistic culture have an independent and autonomous perspective where subjects regarding careers are concerned. The decisions pertaining to career are independent of others and 
the social structure. These people develop self-esteem as they endeavor to proceed independently based on themselves or become successful in their jobs. Contrary to this, individuals in collectivist cultures have an interdependent outlook on subjects related to careers. The career decisions are characterized by the interference of relationships as well as the social structure. The self-respect and success in career of a person are dependent on being on good terms with others or being a part of a larger group (Leong, Hardin and Gupta, 2010). This can be interpreted as prevalence of collectivist culture elements in decision making process.

One of the factors that have been observed within the scope of the study was the low level of participation in student communities and clubs, seminars and conferences by students in university. Within this context it is our opinion that uncertainties regarding career choices could be reduced by encouraging the participation of the students in student communities and clubs, and ensuring satisfactory level of conferences and seminars as this will lead to the diversification of the information sources of the students and increase the individual and environmental awareness. Choosing a career is a complex developmental process that begins in childhood as individuals learn about the range of available career options (Gottfredson, 2002). As the individuals mature in cognitive terms and show progress in the educational system, they gather information on different career prospects, become more aware of the things that inspire them and as such are able to understand their compatibility with potential career choices better (Junk and Armstrong, 2010). Individuals with irregular or inconsistent career selection processes can be considered to have lower self-sufficiency where their career decision making process is considered (Gianakos, 1999). However, the students who had the chance to work as interns and are employed at a job during their university education, have a clearer picture and awareness of what they want to be in the future, where their career choices are concerned. As such it can be said that internships and job experiences could prove to be useful in reducing the indecision of students, where their career choices are concerned. According to the study conducted by Lent, Brown, Talleyrand and McPartland (2002), the activities oriented at career discovery process such as internships and job experiences help students clarify and better understand their interests and skills oriented to specific fields of work and jobs. On the other hand as indicated by Akoğlan Kozak and Dalkıranoğlu (2013), the establishment of the career centers at universities could prove to be useful in determining the requirements and expectations of students and understanding the areas they most need support in. Therefore, it can be said that these types of developments could contribute to the career choices of students ensuring that they take more informed, consistent and accurate decisions in setting up their career paths.

In evaluating the findings of the study the results must be assessed in consideration of the characteristics of the sample that includes students in a specific time period, in a specific field of education, who accepted to be a part of this study. For the prospective studies on a similar subject, spreading the sample to include students from different income levels, in universities in different cities covering a larger sample could prove to be more productive in terms of achieving more comprehensive and comparable results. 


\section{References}

Adams, A., Cox, A. L. (2008). Questionnaires, in-depth interviews and focus groups. In P. Cairns \& A. L. Cox (Eds.), Research Methods for Human Computer Interaction (pp. 17-34). Cambridge, UK: Cambridge University Press,.

Agarwala, T. (2008). "Factors influencing career choice of management students in India", Career Development International, Vol. 13, No. 4, 362-376.

Ahmad, R., Ali, N. A. (2003). "The use of cognitive mapping technique in management research: theory and practice", Management Research News, Vol. 26, No. 7, 116.

Akoğlan Kozak, M., Dalkıranoğlu, T. (2013). "Career perceptions of new graduates: Anadolu University example", Anadolu University Journal of Social Sciences, Vol. 13, No. 1, 41-52.

Ayala, M. P., Oshrit, K. B. (2008). "The role of culture and gender in the choice of a career in management", Career Development International, Vol. 13, No. 4, 306319.

Aycan, Z., Fikret-Pasa, S. (2003). "Career choices, job selection criteria, and leadership preferences in a transitional nation: The case of Turkey", Journal of Career Development, Vol. 30, No. 2, 129-144.

Ballout, H. I. (2007). "Career success: The effects of human capital, personenvironment fit and organizational support", Journal of Managerial Psychology, Vol. 22, No. 8, 741-765.

Chiesa, R., Massei, F., Guglielmi, D. (2016). "Career decision-making self-efficacy change in Italian high school students", Journal of Counseling and Development, Vol. 94, No. 2, 210-224.

Counsell, D. (1999). "Careers in Ethiopia: An exploration of careerists' perceptions and strategies", Career Development International, Vol. 4, No. 1, 46-52.

Derr, C. B., Laurent, A. (1989). The internal and external career: A theoretical and cross-cultural perspective. In M. B. Arthur, D. T. Hall, \& A. Lawrence (Eds.), Handbook of Career Theory (pp. 454-474). Cambridge: Cambridge University Press.

Dhesi, A. S. (2001). "Expectations and post-school choice: some data from India", Education + Training, Vol. 43, No. 1, 14-24.

Dries, N. (2011). "The meaning of career success Avoiding reification through a closer inspection of historical, cultural, and ideological contexts", Career Development International, Vol. 16, No. 4-5, 364-384.

Duffy, R. D., Sedlacek, W. E. (2007). "The work values of first-year college students: Exploring group differences", Career Development Quarterly, Vol. 55, No. 4, 359-364.

Eccles, J. S. (1992). School and family effects on the ontogeny of children's interests, self-perceptions and activity choice. Paper presented at the Nebraska Symposium on Motivation, Lincoln, Nebraska.

Gianakos, I. (1999). "Patterns of career choice and career decision-making selfefficacy", Journal of Vocational Behavior, Vol. 54, No. 2, 244-258.

Gottfredson, L. S. (2002). Gottfredson's theory of circumscription and compromise and self-creation. In D. Brown (Ed.), Career Choice and Development (4th ed., pp. 85-147). San Francisco: Jossey-Bass.

Hofstede, G. (1991). Cultures and Organizations: Software of the Mind, McGraw Hill, London. 
Holland, J. L. (1997). Making Vocational Choice, A Theory of Vocational Personalities and Work Environments, Psychological Assesment Resources, Florida.

Inglehart, R. F. (2008). "Changing values among western publics from 1970 to 2006", West European Politics, Vol. 31, No. 1-2, 130-146.

Johns, N., Ross-Lee, D. (1998). Research methods in service industry, Cassell, London.

Junk, K. E., Armstrong, P. I. (2010). "Stability of career aspirations: A longitudinal test of Gottfredson's theory", Journal of Career Development, Vol. 37, No. 3, 579598.

Krumboltz, J. D. (1976). "A social learning theory of career selection", The Counseling Psychologist, Vol. 6, No. 1, 71-81.

Lent, R. W., Brown, S. D. (1996). "Social cognitive approach to career development: An overview", The Career Development Quarterly, Vol. 44, No. 4, 310-321.

Lent, R. W., Brown, S. D., Hackett, G. (2000). "Contextual supports and barriers to career choice: A social cognitive analysis", Journal of counseling Psychology, Vol. 47, No. 1, 36-49.

Lent, R. W., Brown, S. D., Talleyrand, R., McPartland, E. B. (2002). "Career choice barriers, supports, and coping strategies: College students' experiences", Journal of Vocational Behavior, Vol. 60, No. 1, 61-72.

Leong, F. T. L., Hardin, E. E., Gupta, A. (2010). "A cultural formulation approach to career assessment and career counseling with Asian American clients", Journal of Career Development, Vol. 37, No. 1, 465-486.

Marchall, B., Cardon, P., Poddar, A., Fontenot, R. (2013). "Does sample size matter in qualitative research?: A review of qualitative interviews in is research.", Journal of Computer Information System, Vol. 54, No. 1, 11-22.

Murnane, R., Maynard, R. A., Ohls, J. C. (1981). "Home resources and children's achievement", The Review of Economics and Statistics, Vol. 63, No. 3, 369377.

Nazli, S. (2007). "Career development in primary school children", Career Development International, Vol. 12, No. 5, 446-462.

Ng, E. S. W., Burke, R. J., Fiksenbaum, L. (2008). "Career choice in management: findings from US MBA students", Career Development International, Vol. 13, No. 4, 346-361.

Ozbilgin, M., Kusku, F., Erdogmus, N. (2005). "Explaining influences on career 'choice': the case of MBA students in comparative perspective", International Journal of Human Resource Management, Vol. 16, No. 11, 2000-2028.

Pizzolato, J. E. (2007). "Impossible selves investigating students' persistence decisions when their career-possible selves border on impossible", Journal of Career Development, Vol. 33, No. 3, 201-223.

Robbins, S. B., Wallis, A. B., Dunston, K. T. (2003). "Exploring the academic achievement and career aspirations of college-bound and postsecondary Zulu students", Counseling Psychologist, Vol. 31, No. 5, 593-618.

Super, D. E. (1957). The psychology of careers: An introduction to vocational development, Harper\&Row, New York, NY.

Tanova, C., Karataş Özkan, M., İnal, G. (2008). "The process of choosing a management career", Career Development International, Vol. 13, No. 4, 291305.

Telli Yamamoto, G. (2006). "University evaluation-selection: a Turkish case", International Journal of Educational management, Vol. 20, No. 7, 559-569. 
Thomas, D. C., Inkson, K. (2007). Careers across cultures. In H. Gunz \& M. Peiperl (Eds.), Handbook of Career Studies (pp. 451-470). California, CA: Sage Publications.

Vigoda-Gadot, E., Grimland, S. (2008). "Values and career choice at the beginning of the MBA educational process ", Career Development International, Vol. 13, No. 4, 333-345.

Wong, S. C., Liu, G. J. (2010). "Will parental influences affect career choice? Evidence from hospitality and tourism management students in China", International Journal of Contemporary Hospitality Management, Vol. 22, No. 1, 82-102.

Zikic, J., Richardson, J. (2007). "Unlocking the careers of business professionals following job loss: Sensemaking and career exploration of older workers", Canadian Journal of Administrative Sciences, Vol. 24, No. 1, 58-73. 